\title{
Bonding Characteristics and Flexural Stiffening Effect of Carbon Fibre Reinforced Plastics Strand Sheets Bonded to Steel Beams
}

\author{
Masatsugu Nagai ${ }^{1}$, Yuya Hidekuma ${ }^{2}$, Takeshi Miyashita ${ }^{1}$, Yusuke Okuyama $^{3}$, Akiya Kudo ${ }^{4}$ and Akira \\ Kobayashi $^{2}$ \\ 1. Department of Civil and Environmental Engineering, Nagaoka University of Technology, Niigata 940-2188, Japan \\ 2. Infrastructure Use Division, Composites Company, Nippon Steel \& Sumikin Materials Co., Ltd, Tokyo 103-0024, Japan \\ 3. Department of Civil Engineering, National Institute of Technology, Nagano College, Nagano 381-8550, Japan \\ 4. West Tokyo Operation Bureau, Metroportitan Expressway Co., Ltd, Tokyo 102-0093, Japan
}

\begin{abstract}
Corrosion of steel structures is unavoidable and the structural performance decreases dramatically due to the corrosion. As a repairing method for corroded steel members, bonding carbon fiber sheets with resin had been developed. The purpose of this study is to propose the flexural strengthening method for steel members by using CFRP (carbon fiber reinforced polymer) strand sheets. In order to clarify the stiffening effect and the debonding characteristics of CFRP strand sheets, and to optimize the strengthening design specifications, the flexural tests using high tension steel beams strengthened with CFRP strand sheets are performed. Two cases of experiments are carried out. In Experiment 1, the result from previous research is reflected in the strengthening design. Moreover in Experiment 2, the debonding characteristics obtained from Experiment 1 are reflected. As a result, it was clarified that CFRP strand sheets have stiffening effect equivalent to the theoretical value and its debonding property is practically high enough when FRP (fiber reinforcement polymer) sheets have an appropriate bonding length.
\end{abstract}

Key words: CFRP strand sheets, corrosion, debonding, flexural strengthening, steel members.

\section{Introduction}

Corrosion of steel structures is unavoidable and the structural performance decreases due to the corrosion. As a repairing method for corroded steel members of which cross-sectional area is reduced, a method to bond the carbon fiber sheet with resin to steel members has been studied [1]. This method is known as an efficient and economical method for repairing because no heavy equipment is necessary at work site. As for common reinforcing method, the continuous fiber sheet [2] and the FRP (fiber reinforcement polymer) strip [3] are being used. However, there exist some demerits on employing these materials.

Corresponding author: Yuya Hidekuma, M.Sc., chief, research fields: composite materials, FRP strengthening of metallic structures. E-mail: y-hidekuma@nck.nsmat.co.jp.
When using continuous fiber sheets, adhesion defects may be caused by poor impregnation of resin. When also using FRP strips, debonding may occur at lower load because of interfacial shearing stress concentrated between steel and FRP at its tips [4].

In recent years, to solve these problems, the FRP strand sheet (Fig. 1) which consists of bunch of individually hardened continuous fiber strands was developed [4]. It is expected that no defects occur by using the FRP strand sheets because it is impregnated with resin and hardened at factory beforehand. Furthermore, the FRP strand sheet can reduce necessary layers of a sheet compared to continuous fiber sheets because of its high mass per unit area.

The purpose of this study is to propose the flexural strengthening method for steel members by using CFRP 


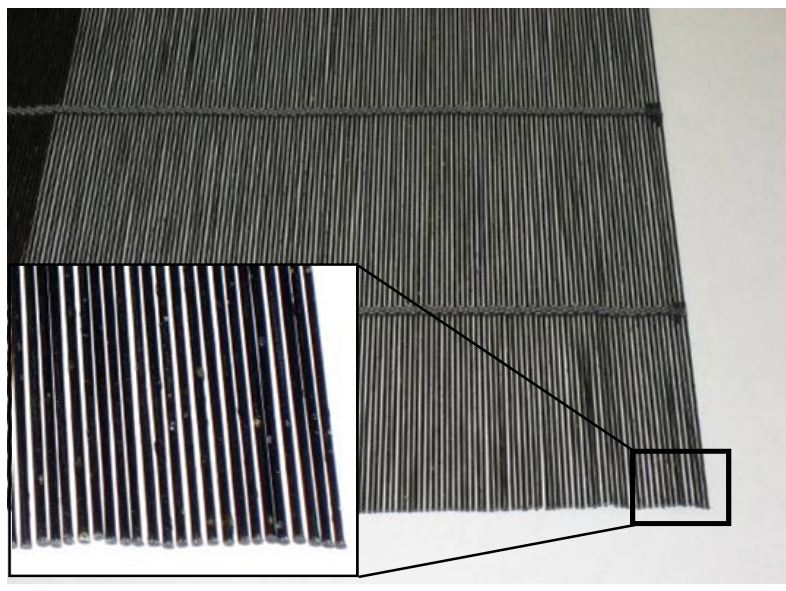

Fig. 1 CFRP strand sheets.

(carbon fiber reinforcement polymer) strand sheets. In order to clarify the stiffening effect and the debonding characteristics of CFRP strand sheets and to optimize the strengthening design specifications, the flexural tests using high tension steel beams strengthened with CFRP strand sheets are performed. Two cases of experiments are carried out. These experiments are called Experiments 1 and 2, respectively. In Experiment 1, the result from previous research [4] is reflected in the strengthening design. Moreover, in Experiment 2, the debonding characteristics obtained from Experiment 1 are reflected. In this study, the effects of the overlap splice joint (Fig. 2) of CFRP strand sheets are also examined.

\section{Experiment 1}

\subsection{Materials}

As a base metal, SBHS700 (JIS G3128: high yield strength steel plates for welded structure) steel is used. Its yield stress is $836 \mathrm{MPa}$ and elastic modulus is 200 $\mathrm{GPa}$. The reason for using the high yield strength steel is to observe the debonding characteristics under large strain. CFRP strand sheets are used for reinforcements.
The material properties of CFRP strand sheets are listed in Table 1.

\subsection{Outline of Tests}

Two H-shaped steel girders are used to conduct flexural tests. CFRP strand sheets are bonded to lower flanges. The three-point loading tests are performed until yield load of steel $(1,020 \mathrm{kN})$ or until debonding of CFRPs occurs. Measured values are deflection and strain in CFRP/steel. Debonding of CFRP is also observed. The experimental parameters are the bonding length of each layer and the presence or absence of overlapped splice joint as listed in Table 2. The specimens are shown in Fig. 3. F10B has four overlapped splice joints from 1st layer to 3 rd layer as shown in Fig. 3. The ply number of CFRP strand sheets is 10 layers in Specimen F10A. Specimen F10B has 11 layers because the ply number becomes one layer fewer at overlap splice joints. Therefore, the stiffening effect of F10A and F10B should be the same.

\subsection{Design Method}

The minimum bonding length of each layer for obtaining the theoretical stiffening effect can be calculated by following equations:

$$
I_{i}=I_{s}+\frac{E_{c f}}{E_{s}}\left(I_{c f}+A_{c f} \cdot e_{c f}^{2}\right)
$$

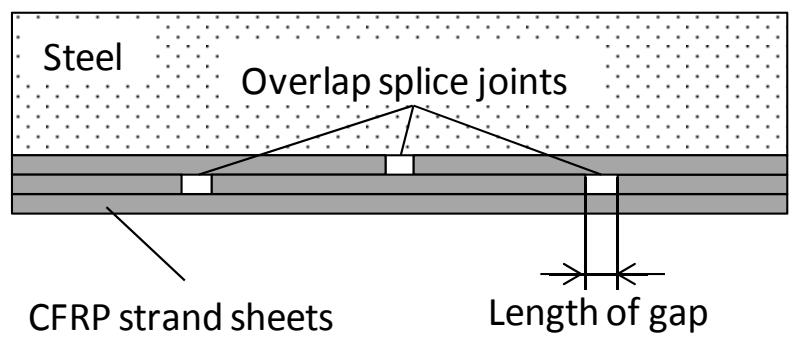

Fig. 2 Schematic drawing of overlap splice joint.

Table 1 Material properties of CFRP strand sheets.

\begin{tabular}{lllllll}
\hline \multirow{2}{*}{ Sheet } & $\begin{array}{l}\text { Mass per } \\
\text { unit area } \\
\left(\mathrm{g} / \mathrm{m}^{2}\right)\end{array}$ & $\begin{array}{l}\text { Design } \\
\text { thickness } \\
(\mathrm{mm})\end{array}$ & $\begin{array}{l}\text { Elastic modulus } \\
\left(\mathrm{kN} / \mathrm{mm}^{2}\right)\end{array}$ & $\begin{array}{l}\text { Tensile strength } \\
\left(\mathrm{N} / \mathrm{mm}^{2}\right)\end{array}$ & $\begin{array}{l}\text { Elastic modulus } \\
\left(\mathrm{kN} / \mathrm{mm}^{2}\right)\end{array}$ & $\begin{array}{l}\text { Tensile strength } \\
\left(\mathrm{N} / \mathrm{mm}^{2}\right)\end{array}$ \\
\hline Experiment 1 (SSHM900) & 900 & 0.429 & 640 & 1,900 & 695 & 2,670 \\
Experiment 2 (SSHM900) & 900 & 0.429 & 640 & 1,900 & 721 & 2,970 \\
\hline
\end{tabular}


Table 2 Parameters of Experiment 1.

\begin{tabular}{lllllll}
\hline Specimen & Number of ply & $\begin{array}{l}\text { Length of 1st layer } \\
(\mathrm{mm})\end{array}$ & $\begin{array}{l}\text { Length of overmost layer } \\
(\mathrm{mm})\end{array}$ & $\begin{array}{l}\text { Length of step } \\
(\mathrm{mm})\end{array}$ & Number of joints & $\begin{array}{l}\text { Length of gap } \\
(\mathrm{mm})\end{array}$ \\
\hline F10A & 10 & 2,360 & 920 & 80 & 0 & - \\
F10B & $10+1$ & 3,900 & 900 & 150 & 4 & 0 \\
\hline
\end{tabular}
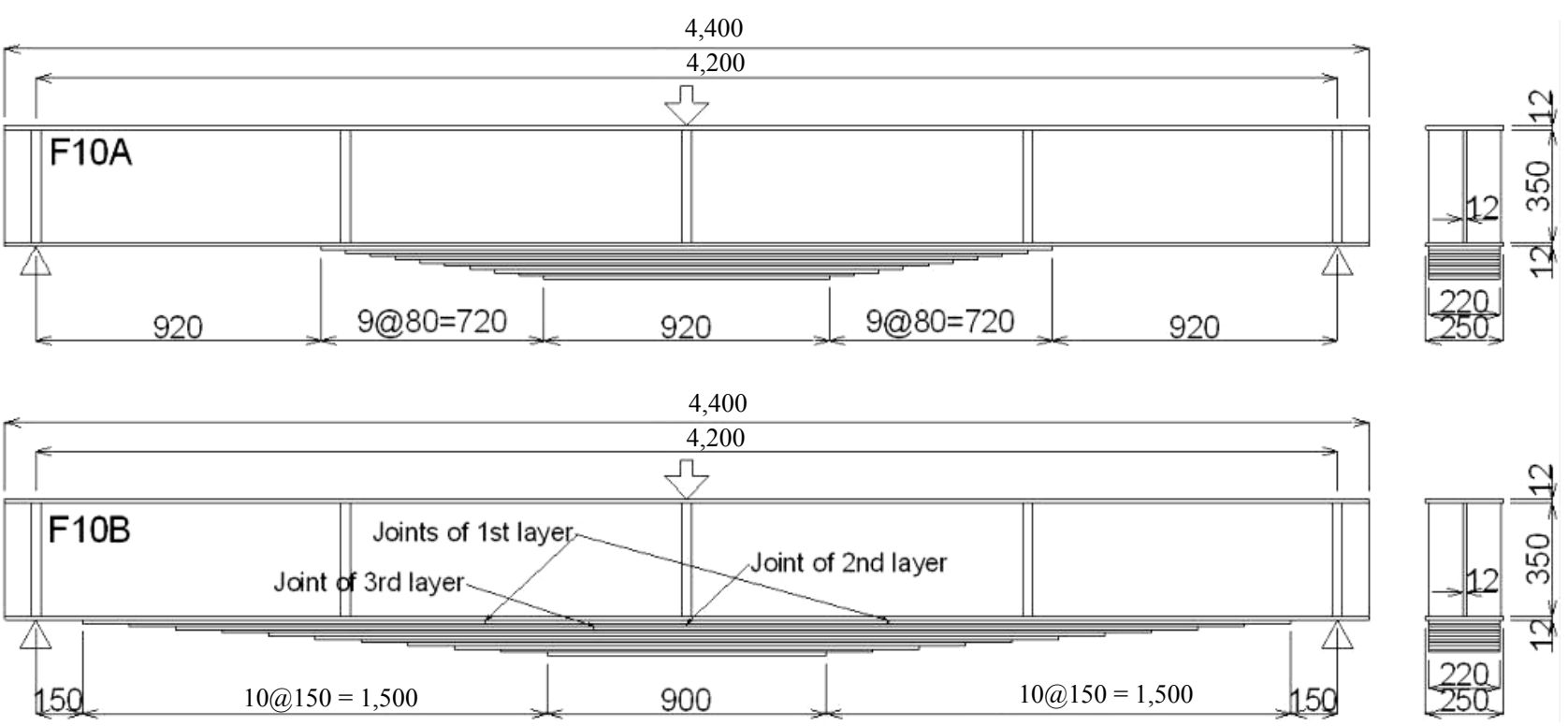

Fig. 3 Specimens of Experiment 1 (unit: $\mathbf{m m}$ ).

$$
x_{i}=\frac{2 \sigma_{m} I_{i-1}}{y_{i-1} P_{y}}
$$

where:

$E_{s}, E_{c f}$ : elastic modulus of steel and CFRP;

$I_{i}$ : geometrical moment of inertia of composite cross-section at $i$ th layer;

$I_{s}, I_{c f}$ : geometrical moment of inertia of steel and CFRP;

$A_{c f}:$ cross-sectional area of CFRP;

$y_{i}$ : distance from neutral axis to optional location;

$e_{c f}$. distance from neutral axis to centroid of CFRP;

$x_{i}$ : position of end of $i$ th layer of CFRP from the supporting point;

$\sigma_{m}$ : stress of steel at the end of $i$ th layer of CFRP;

$P_{y}$ : flexural load at center.

In this study, $P_{y}$ is $1,020 \mathrm{kN}$ which is the yield load of the unreinforced steel and $\sigma_{m}$ is $460 \mathrm{MPa}$ which is the stress of reinforced steel at 1,020 kN. Substituting these values into Eq. (2) yields the minimum bonding length of each layer. Normally, the load transfer length is necessary when bonding the CFRP to the structure. In previous research [4], that length was more than $100 \mathrm{~mm}$. In this study, $200 \mathrm{~mm}$ is adopted as load transfer length. Therefore, the bonding length is further extended to $200 \mathrm{~mm}$ on one side.

When strengthening steel members with CFRP, debonding of CFRP is the great concern. Normally, the debonding occurs between the steel and the 1st layer of CFRP. Therefore, it is necessary to consider debonding in designing the length of the 1st layer. In previous research [4], steel stress at tip of the 1st layer of the CFRP strand sheet is $280 \mathrm{MPa}$ when debonding occurs. Therefore, substituting $280 \mathrm{MPa}$ into Eq. (2) as $\sigma_{m}$ yields the debonding load of 1st layer of CFRP. In the case of F10A, the debonding of the 1st layer of CFRP would occur at $780 \mathrm{kN}$. In the case of F10B, the debonding would not occur because the length of the 1st layer is extended to near supporting points where the bending moment is nearly 0 . The lengths of step in each layer of F10A and F10B are the same. 


\subsection{Results and Discussion}

\subsubsection{Stiffening Effect}

The load-strain curves of F10A and F10B are shown in Fig. 4. From this figure, it is found that the strains of the steel and the CFRP agree well with the theoretical values in both specimens. Table 3 presents the experimental flexural rigidity $\left(E I_{\exp }\right)$, theoretical flexural rigidity $\left(E I_{\text {cal }}\right)$ and achievement ratio $\left(E I_{\text {exp }} / E I_{\text {cal }}\right)$, and the fracture state at each load. The theoretical flexural rigidities are calculated using Eq. (1). In this table, the achievement ratios of flexural rigidities are almost $100 \%$ in spite of presence or absence of the overlap splice joint. It means that the proposed design method regarding stiffening effect is

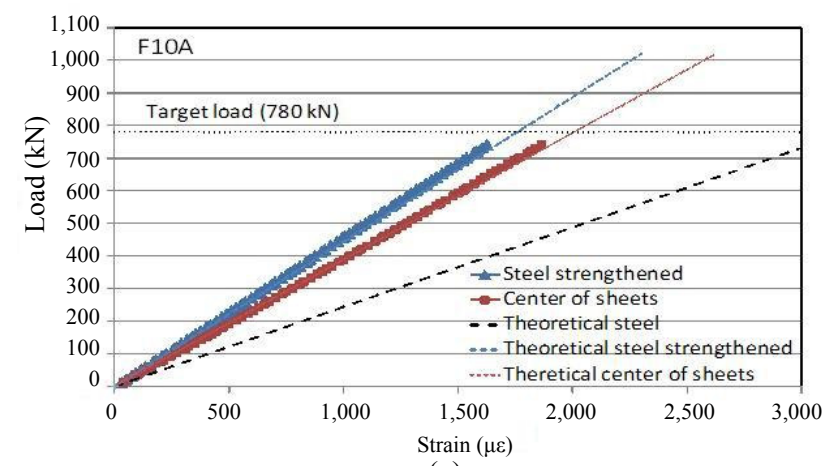

(a) correct.

\subsubsection{Debonding Property}

From Table 3 , it is observed that the proposed design method regarding debonding property is not correct. In the case of F10A, the debonding occurred between the 2nd and the 3rd layer of CFRP strand sheet, although the debonding load almost agrees with that of designed value. In F10B, debonding also occurred between the 11th layer and the 10th layer. These results mean that the debonding at interlayer of CFRP needs to be considered in the design.

Table 4 presents the calculated value of the stresses and strains of the steel and the CFRP strand sheet at each fracture state. In this table, values of States $\mathrm{A} 1, \mathrm{~B} 1$ and $\mathrm{B} 2$ regarding the debonding are theoretical

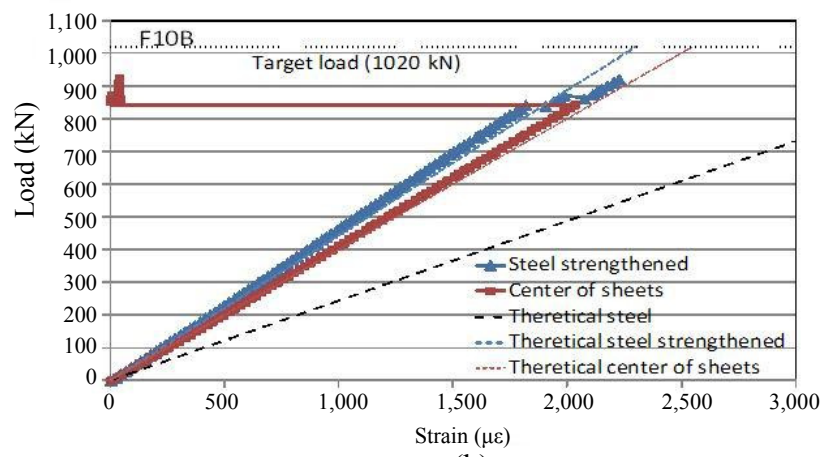

(b)

Fig. 4 The load-strain curves of: (a) F10A; (b) F10B.

Table 3 The results of Experiment 1.

\begin{tabular}{|c|c|c|c|c|c|c|}
\hline \multirow{2}{*}{ Specimen } & \multicolumn{3}{|c|}{ Flexural rigidity } & \multirow{2}{*}{-Load (kN) } & \multirow{2}{*}{ Fracture state } & \multirow{2}{*}{ State No.* } \\
\hline & $\overline{E I_{\exp }\left(\mathrm{kN} \cdot \mathrm{mm}^{2}\right)}$ & $E I_{\text {cal }}\left(\mathrm{kN} \cdot \mathrm{mm}^{2}\right)$ & Achievement (\%) & & & \\
\hline \multirow{2}{*}{ F10A } & \multirow{2}{*}{67,809} & \multirow{2}{*}{65,672} & \multirow{2}{*}{103.3} & 742 & Debonding from 3rd layer & A1 \\
\hline & & & & 881 & Tensile rupture at center & $\mathrm{A} 2$ \\
\hline \multirow{3}{*}{ F10B } & \multirow{3}{*}{68,752} & \multirow{3}{*}{65,672} & \multirow{3}{*}{104.7} & 842 & Debonding of 11th layer & B1 \\
\hline & & & & 873 & Debonding of 10th layer & $\mathrm{B} 2$ \\
\hline & & & & 922 & Tensile rupture at center & B3 \\
\hline
\end{tabular}

*Each fracture state is defined as A1, A2, B1, B2 and B3

Table 4 Calculated value of stress and strain in each fracture state.

\begin{tabular}{lllllllll}
\hline Specimen & $\begin{array}{l}\text { State } \\
\text { No. }\end{array}$ & $\begin{array}{l}\text { Load } \\
(\mathrm{kN})\end{array}$ & $x_{i}(\mathrm{~mm})$ & $\begin{array}{l}\text { Moment } \\
(\mathrm{kN} \cdot \mathrm{mm})\end{array}$ & $\begin{array}{l}\text { Stress of steel } \\
\left(\mathrm{N} / \mathrm{mm}^{2}\right)\end{array}$ & $\begin{array}{l}\text { Strain of steel } \\
(\mu \varepsilon)\end{array}$ & $\begin{array}{l}\text { Stress of sheet } \\
\left(\mathrm{N} / \mathrm{mm}^{2}\right)\end{array}$ & $\begin{array}{l}\text { Strain of sheet } \\
(\mu \varepsilon)\end{array}$ \\
\hline \multirow{2}{*}{ F10A } & A1 & 742 & 1,080 & 400,583 & 269 & 1,347 & 958 & 1,378 \\
& A2 & 881 & 2,100 & 925,029 & 622 & 3,111 & 2,211 & 3,182 \\
\hline \multirow{3}{*}{ F10B } & B1 & 842 & 1,650 & 694,502 & 313 & 1,563 & 1,221 & 1,757 \\
& B2 & 873 & 1,500 & 654,615 & 309 & 1,547 & 1,191 & 1,714 \\
& B3 & 922 & 2,100 & 967,806 & 458 & 2,288 & 1,761 & 2,534 \\
\hline
\end{tabular}


values at the end of debonding layer, as well as values of state A2 and B3 regarding the tensile rupture of CFRP strand sheets are theoretical values at the center of span. The steel stress of state B1 agrees with that of state B2. The steel stress of state A1 should agree as well. However, the result shows that they are lower than those of B1 and B2. In F10A, the rapid load transfer occurs near the vertical stiffening plate. This causes the occurrence of debonding at lower stress in F10A. It should be noted that the debonding of CFRP is likely to occur near the stiffening plate. The results from F10B reveal that the steel stress is about 310 MPa when debonding occurs at interlayer of CFRP.

In Table 4, it is found that the CFRP stress of state B3 is lower than that of A2. The tensile strength in F10B is lower than the guaranteed tensile strength of CFRP although the tensile strength in F10A is higher than that of CFRP. It can be considered that the reason of the tensile strength reduction is the stress concentration at the overlap splice joint. Therefore, a gap of several millimeters between the CFRP strand sheets is required at overlap splice joint in order to reduce the stress concentration.

\section{Experiment 2}

\subsection{Outline of Tests}

The findings from Experiment 1 are as follows:

- In previous research, the steel stress at tip of $1 \mathrm{st}$ layer of which debonding of CFRP strand sheet occurred was $280 \mathrm{MPa}$;
- The steel stress when debonding occurred at interlayer of CFRP was around $310 \mathrm{MPa}$;

- Several millimeters gap between the CFRP strand sheets is required at overlap splice joint.

In Experiment 2, these findings are reflected to the design method. The steel stress, when debonding occurs at interlayer of CFRP, is decided as $300 \mathrm{MPa}$. The gap length between the CFRP strand sheets is also decided as $20 \mathrm{~mm}$, which takes into consideration of the fabrication error. The experimental parameters are listed in Table 5. F10D has five overlap splice joints from the 1st layer to the 4th layer. In the case of F10C, the length of the 1st layer is designed upon the assumption that debonding would occur at $650 \mathrm{kN}$ and the other layer is designed upon the assumption that debonding would not occur until $650 \mathrm{kN}$. In the case of F10D, no fracture would occur until 1,020 kN.

\subsection{Results and Discussion}

Table 6 presents the experimental flexural rigidity, the theoretical flexural rigidity, the achievement ratio and the fracture state. The theoretical flexural rigidities are calculated using Eq. (1). In this table, the achievement ratios of flexural rigidities are almost $100 \%$. From Table 6, it is found that the fracture modes of F10C and F10D agree with the assumption based on the proposed design method. The debonding load of F10C is $815 \mathrm{kN}$, which is higher than designed value. The steel stress at tip of the 1st layer of which debonding of CFRP strand sheet occurred is $350 \mathrm{MPa}$.

Table 5 Parameters of Experiment 2.

\begin{tabular}{lllcccc}
\hline Specimen & Number of ply & $\begin{array}{l}\text { Length of 1st layer } \\
(\mathrm{mm})\end{array}$ & $\begin{array}{l}\text { Length of overmost layer } \\
(\mathrm{mm})\end{array}$ & $\begin{array}{l}\text { Length of step } \\
(\mathrm{mm})\end{array}$ & $\begin{array}{l}\text { Number of } \\
\text { joints }\end{array}$ & $\begin{array}{l}\text { Length of gap (mm) } \\
\text { F10C }\end{array} 10$ \\
F10D & $10+1$ & 3,000 & 740 & 70 & 0 & - \\
\hline
\end{tabular}

Table 6 Results of Experiment 2.

\begin{tabular}{llllll}
\hline \multirow{2}{*}{ Specimen } & \multicolumn{3}{c}{ Flexural rigidity } & Load & \multirow{2}{*}{ Fracture state } \\
\cline { 2 - 5 } & $E I_{\text {exp }}\left(\mathrm{kN} \cdot \mathrm{mm}^{2}\right)$ & $E I_{\text {cal }}\left(\mathrm{kN} \cdot \mathrm{mm}^{2}\right)$ & Achievement $(\%)$ & $(\mathrm{kN})$ & \\
\hline F10C & 66,700 & 66,171 & 100.8 & 815 & Debonding from the 1st layer \\
F10D & 68,594 & 66,171 & 103.7 & - & No fracture \\
\hline
\end{tabular}


This value is higher than that of the previous research. However, in this study, the steel stress when the debonding occurs at tip of the 1st layer of CFRP strand sheet is decided as $280 \mathrm{MPa}$ in consideration of safety. In the case of F10D, the debonding at interlayer of CFRP strand sheet and the rupture of strand sheet at joint did not occur until $1,020 \mathrm{kN}$. It means that the proposed design methods regarding debonding at interlayer of CFRP and gap between strand sheets at joint are correct.

\section{Conclusions}

In order to clarify the stiffening effect and debonding characteristics of CFRP strand sheets and to optimize the strengthening design specifications, the flexural tests, using high strength steel beams strengthened with CFRP strand sheets, were performed. The results obtained from this research are summarized as follows:

(1) The steel beam strengthened with CFRP strand sheets can be designed as composite cross section;

(2) The steel stress at the tip of the 1st layer of which debonding of CFRP strand sheet occurred was $280 \mathrm{MPa}$;

(3) The steel stress when the debonding occurred at interlayer of CFRP strand sheet was $310 \mathrm{MPa}$;
(4) A $20 \mathrm{~mm}$ gap between the CFRP strand sheets is required at overlap splice joint;

(5) The flexural test results of the specimens, which were designed based on the above findings, exactly agreed with the designed value. Hence, in order to establish the optimal flexural design method for steel members using CFRP strand sheets, it is important to consider and reflect in design of these results.

\section{References}

[1] Cadei, J. M. C., Stratford, T. J., Hollaway, L. C., and Duckett, W. G. 2004. Strengthening Metallic Structures Using Externally Bonded Fibre-Reinforced Polymers. London: CIRIA (Construction Industry Research and Information Association) Publication.

[2] Sugiura, H., Kobayashi, A., Inada, N., Honma, A., Ohgaki, K., and Nagai, M. 2009. “A Proposal of Design and Construction Method of Repair for Corroded Steel Member by Carbon Fiber Sheets." Journal of Construction Management and Engineering 65 (1): 106-18.

[3] Lenwari, A., Thepdhatri, T., and Albrecht, P. 2006. "Debonding Strength of Steel Beams Strengthened with CFRP Plates." Journal of Composites for Construction 10 (1): 69-78.

[4] Hidekuma, Y., Kobayashi, A., Tateishi, A., Nagai, M., and Miyashita, T. 2010. "Repairing Method for the Steel Members by CFRP Strand Sheets." In Proceedings of the 5th International Conference on FRP Composites in Civil Engineering, 881-5. 